\title{
Associations of Medication Regimen Complexity with COPD Medication Adherence and Control
}

\author{
Alex D Federman' \\ Rachel O'Conor ${ }^{2}$ \\ Michael S Wolf ${ }^{2}$ \\ Juan P Wisnivesky' \\ 'Division of General Internal Medicine, \\ Icahn School of Medicine at Mount Sinai, \\ New York, NY, USA; ${ }^{2}$ Division of General \\ Internal Medicine, Feinberg School of \\ Medicine, Northwestern University, \\ Chicago, IL, USA
}

\begin{abstract}
Introduction: Medication adherence is often low among people with chronic obstructive pulmonary disease (COPD) and medication regimen complexity may be a contributing factor. In this study, we sought to examine the role of medication regimen complexity in COPD medication adherence among patients with multimorbidity.

Methods: We performed cross-sectional analysis of data on COPD patients in primary care and pulmonary practices in New York City and Chicago $(n=400)$. Regimen complexity was represented by the medication regimen complexity index (MRCI) and simple medication count. Adherence was measured by self-report and inhaler dose counts. Disease control measures included the COPD severity score (COPDSS) and the Medical Research Council (MRC) severity index.

Results: Mean age of study participants was 69 years, $66 \%$ had MRC grades 4 or 5, and $45 \%$ had low medication adherence. MRCI scores did not differ significantly between those with and without adequate medication adherence. Patients with higher MRCI scores were more likely to have severe COPD (OR 5.00, 95\% CI 1.46-17.1, p=0.01) and dyspnea grades 3 or 4 (OR 2.27, 95\% CI 1.03-5.03, $\mathrm{p}=0.04$ ). Significant associations of medication count with COPD severity were also observed.

Discussion: These findings demonstrate that among patients with COPD and comorbid hypertension and diabetes, higher medication regimen complexity is associated with worse COPD control but not with COPD medication adherence.
\end{abstract}

Keywords: chronic obstructive pulmonary disease, multimorbidity, medication regimen complexity, medication adherence

\section{Introduction}

Regular and routine use of medications is the mainstay of treatment for chronic obstructive pulmonary disease (COPD), and yet adherence to inhaled medications among people with COPD is typically poor, with about half using their medications as prescribed. ${ }^{1-5}$ There are many well documented barriers to medication adherence, like costs, limited health literacy, and concerns about medications. ${ }^{6-8}$ Another potentially important contributor to low adherence rates is the number and complexity of the patient's medication regimen. With more than three-quarters of COPD patients having 4 or more co-occurring chronic medical conditions, the burden of managing and taking many medications could potentially overwhelm individuals, resulting in underuse. ${ }^{9}$ Given the large number of medications taken by older adults with COPD, one study documented a median of 6 and range of $2-14,{ }^{10}$ medication regimen complexity deserves more scrutiny for its role in medication non-adherence among people with COPD than it has received over the years.
Correspondence: Alex D Federman Division of General Internal Medicine, Icahn School of Medicine at Mount Sinai, I Gustave L. Levy Place, New York, NY, 10029, USA

Tel + I $212824-7565$

Fax + I 212 824-2317

Email alex.federman@mssm.edu 
Research on the association of medication regimen complexity with adherence and other clinical outcomes has been mixed. ${ }^{11-14}$ Some have shown poorer medication adherence, as well as poorer clinical performance, with increased regimen complexity, whereas others have reported null associations. Few studies have specifically examined the impact of regimen complexity on medication adherence and clinical outcomes among patients with COPD. In this study, we sought to determine the association of medication regimen complexity with medication adherence and disease control among US adults with COPD and comorbid hypertension and diabetes.

\section{Methods}

\section{Sample and Procedure}

Data used for these analyses are from the COPD multimorbidity (MM) study, ${ }^{5}$ a longitudinal cohort study of patients with COPD and comorbid hypertension, diabetes, or both conditions. Patients were recruited from primary care and pulmonary practices in hospital and communitybased settings in New York City, New York and Chicago, Illinois. They were eligible to participate if they were community-dwelling, spoke English or Spanish, had a diagnosis of COPD (not confirmed by spirometry), a $\geq 15$ pack-year smoking history, a current prescription for an inhaled corticosteroids (ICS), long-acting betaagonist (LABA) or long-acting anticholinergic, and comorbid hypertension and/or diabetes with at least one current prescribed medication for the treatment of each. Patients were excluded if they had other non-COPD chronic respiratory illnesses or documentation of dementia in the electronic health record.

Participants completed structured interviews at 5-month intervals over a 15 -month period. Data for the present analyses are from baseline interviews. All participants provided written informed consent and the study protocol was approved by the Institutional Review Boards of the Icahn School of Medicine at Mount Sinai and the Northwestern University Feinberg School of Medicine.

\section{Medicine Regimen Complexity and Total Medication Count}

Medication regimen complexity was the primary independent variable and was calculated using the Medication Regimen Complexity Index (MRCI). ${ }^{15}$ The MRCI quantifies the complexity of the patient's entire medication regimen by assigning weights to dosage formulations, dosing frequencies and additional administration directions, including route. Trained research coordinators reviewed the directions for each prescribed medication from participant's electronic health record and recorded the form, dosing frequency and additional directions based on the established categories presented. They also summed the total number of medications that were prescribed for routine use for the total medication count. We did not include medications prescribed pro re nata (PRN) in calculating the MRCI or total medication count.

\section{Medication Adherence}

We measured adherence to inhaled COPD controller medications, and oral hypertension and diabetes medications. All approaches to measuring medication adherence have limitations with respect to accuracy and feasibility. ${ }^{16}$ For COPD medications, we used two measures, self-report and review of dose counters on participants' inhalers over a 30-day period. Hypertension and diabetes medication adherence were measured only by self-report. To assess self-reported medication adherence, we used the 10-item Medication Adherence Rating Scale (MARS), ${ }^{17}$ which has been validated for use with inhaled and oral medications and was designed to limit problems of social desirability bias. Scores range from 1 to 5, with higher scores indicating better adherence. Scores are averaged for the 10 items and mean MARS score $\geq 4.5$ indicates adequate medication adherence. ${ }^{18}$ For dose counts on inhaler devices, the research staff examined inhalers during the scheduled interviews then contacted participants by telephone 30 days later to record the number of doses remaining. Adherence was calculated by the total doses taken divided by the total doses prescribed during the 30-day period, and adherence was classified as poor $(<80 \%)$ or adequate $(\geq 80 \%)$ per convention.

\section{Measures of Disease Control}

Secondary outcomes were COPD severity, dyspnea, and hypertension and diabetes control. COPD severity was assessed using the COPD Severity Score (COPDSS), which quantifies severity by assessing current symptoms and treatments. ${ }^{19}$ Possible scores range from 0 to 35 , and higher scores indicate worse severity. Scores $>1$ standard deviation above the mean were defined as high severity. We also graded self-reported dyspnea during routine daily activities using the 5-item Medical Research Council (MRC) dyspnea scale, and defined the outcome as MRC score $\geq 4$, indicating a high level of dyspnea. ${ }^{20}$ To determine hypertension control, 
trained research coordinators assessed systolic and diastolic blood pressure during in-person interviews. After a 5 minute rest period, the research coordinator obtained 3 blood pressure measures at 5-minute intervals with the patient seated using an automated device (Omron Intellisense, Omron Healthcare, Inc., Kyoto, Japan). ${ }^{21}$ We used the average of the systolic and diastolic blood pressures and defined blood pressure control as systolic $<130 \mathrm{mmHg}$ and diastolic $<80$ $\mathrm{mmHg}$ for individuals with cardiovascular disease or diabetes or systolic $<140 \mathrm{mmHg}$ and diastolic $<85 \mathrm{mmHg}$ for all others. $^{22}$ To determine control of diabetes, we abstracted the chart for the most recent hemoglobin A1c value measured and documented in the 4 months prior to the interview. Diabetes control was defined as hemoglobin A1c $<8 \%{ }^{23}$

\section{Covariates}

Since depression is highly prevalent among COPD patients and affects medication adherence and perception of symptoms, ${ }^{24,25}$ we controlled for depression in the primary analyses. Depression was identified through the Depression Interview and Structured Hamilton (DISH), a structured diagnostic interview, validated for diagnosing major depression and for telephone administration. ${ }^{26}$ The DISH was administered by trained psychology graduate students by telephone 1-3 days after the in-person interview. Health literacy was included as a covariate as well because of its strong association with chronic illness self-management behaviors, including COPD medication use. ${ }^{2}$ It was assessed with a single item question about the respondent's confidence completing health forms. ${ }^{27}$ Low health literacy was defined as being somewhat to not at all confident in their ability to complete the task. We assessed cognition, another contributor to self-management behaviors among COPD patients, ${ }^{2}$ using the Trail Making Test Part B, which measures executive function. ${ }^{28}$ We also included sociodemographic and general health status measures.

\section{Data Analysis}

We used the $t$-test to assess the association of the normally distributed MRCI values, as a continuous measure, with the primary outcome (medication adherence for COPD [self report and dose count], hypertension, and diabetes) and secondary outcomes of disease control (COPDSS, MRC scale, blood pressure, HbAlc). We also created a 4-level categorical variable for the MRCI based on the quartile distribution of scores for ease of interpretation and tested its association with these outcomes using the chisquare test. We performed multivariate logistic regression modelling of the COPD, hypertension, and diabetes adherence and clinical outcome measures, adjusting for the previously described covariates. All analysis were conducted in SAS, version 9.4 (SAS Institute, Cary, NC).

\section{Results}

\section{Recruitment and Subject Characteristics}

The mean age of study participants was 68.8 (8.7) years and approximately half $(47.1 \%)$ were aged 70 years and older (Table 1). Male participants comprised 38.8\% of the sample, $35.1 \%$ were Black and $16.7 \%$ Hispanic, and

Table I Baseline Characteristics of Study Population, N=400

\begin{tabular}{|l|c|}
\hline & $\mathbf{N}(\%)$ \\
\hline Age, mean years (SD) & $68.8(8.7)$ \\
\hline $\begin{array}{l}\text { Age Category } \\
50-59 \\
60-69\end{array}$ & $63(15.8)$ \\
$70-79$ & $149(37.3)$ \\
$80+$ & $139(34.8)$ \\
\hline Male Sex & $49(12.3)$ \\
\hline Race and ethnicity & $155(38.8)$ \\
\hline White, non-Hispanic & \\
Black, non-Hispanic & $162(40.9)$ \\
Hispanic & $139(35.1)$ \\
Other & $66(16.7)$ \\
\hline Education & $29(7.3)$ \\
\hline High school or less & \\
High school graduate & $63(15.9)$ \\
Some college & $88(22.2)$ \\
College graduate & $117(29.5)$ \\
\hline English Proficiency, good-excellent & $129(32.5)$ \\
\hline Low health literacy & $334(84.1)$ \\
\hline Insurance & $93(23.5)$ \\
\hline $\begin{array}{l}\text { Medicare + Medicaid } \\
\text { Medicaid or self-pay }\end{array}$ & $98(24.7)$ \\
\hline Private & $51(13.4)$ \\
\hline Diabetes mellitus & $47(11.8)$ \\
\hline Depression (n=363) & $199(50.1)$ \\
\hline Impairment of executive function (n=366) & $386(96.7)$ \\
\hline Number of prescribed medications, mean (SD) & $60.8)$ \\
\hline
\end{tabular}

Abbreviations: $\mathrm{MRCl}$, medication regimen complexity index; COPD, chronic obstructive pulmonary disease. 
Table 2 Association of MRCI Scores and Medication Counts with COPD, Hypertension, and Diabetes Medication Adherence

\begin{tabular}{|c|c|c|c|c|c|c|c|c|}
\hline & \multicolumn{2}{|c|}{$\begin{array}{l}\text { COPD Medication } \\
\text { (Self-Report) }\end{array}$} & \multicolumn{2}{|c|}{$\begin{array}{l}\text { COPD Medication } \\
\text { (Dose Count) }\end{array}$} & \multicolumn{2}{|c|}{$\begin{array}{c}\text { Hypertension Medication } \\
\text { (Self-Report) }\end{array}$} & \multicolumn{2}{|c|}{$\begin{array}{c}\text { Diabetes Medication } \\
\text { (Self-Report) }\end{array}$} \\
\hline & Low & Adequate & Low & Adequate & Low & Adequate & Low & Adequate \\
\hline $\mathrm{N}(\%)$ & $175(45.0)$ & $214(55.0)$ & $172(52.6)$ & $155(47.4)$ & $110(28.9)$ & $270(7 I .1)$ & $47(38.8)$ & $74(6 \mid .2)$ \\
\hline $\mathrm{MRCl}$, mean (sd) & $33.5(13.4)$ & $32.0(14.8)$ & $32.7(13.6)$ & $31.5(13.6)$ & $32.6(13.5)$ & $32.8(14.8)$ & $39.1(14.4)$ & $38.3(15.7)$ \\
\hline \# Medications, mean (sd) & II.7 (4.5) & $12.0(5.0)$ & II.8 (4.7) & $12.0(4.7)$ & II.0 (4.0) & $12.3(5.2)^{*}$ & I $3.0(4.2)$ & $14.9(5.2)^{*}$ \\
\hline \multicolumn{9}{|l|}{$\mathrm{MRCl}, \%$} \\
\hline $\mathrm{I}^{\text {st }}$ quartile (5-22) & 24.0 & 23.8 & 19.8 & 28.4 & 26.4 & 24.1 & 13.0 & 14.1 \\
\hline $2^{\text {nd }}$ quartile $(23-30)$ & 21.1 & 29.9 & 29.1 & 25.2 & 25.5 & 25.6 & 21.7 & 16.9 \\
\hline $3^{\text {rd }}$ quartile $(3 \mid-42)$ & 25.1 & 24.8 & 25.6 & 23.9 & 19.1 & 25.9 & 17.4 & 28.2 \\
\hline $4^{\text {th }}$ quartile (43-82) & 29.7 & 21.5 & 25.6 & 22.6 & 29.1 & 24.4 & 47.8 & 40.9 \\
\hline \multicolumn{9}{|l|}{ \# Medications, \% } \\
\hline $\mathrm{I}^{\text {st }}$ quartile $(2-8)$ & 28.6 & 24.3 & 27.9 & 21.9 & 28.2 & 26.3 & 15.2 & 9.9 \\
\hline $2^{\text {nd }}$ quartile $(9-1 \mathrm{I})$ & 23.4 & 26.6 & 20.9 & 31.6 & 30.0 & 22.6 & 21.7 & 18.3 \\
\hline $3^{\text {rd }}$ quartile $(12-15)$ & 28.0 & 25.7 & 31.4 & 25.2 & 28.2 & 25.2 & 37.0 & 25.4 \\
\hline $4^{\text {th }}$ quartile $(16-29)$ & 20.0 & 23.4 & 19.8 & 21.3 & 13.6 & 25.9 & 26.0 & 46.5 \\
\hline
\end{tabular}

Note: $* \mathrm{P}<0.05$.

Abbreviations: $\mathrm{MRCl}$, medication regimen complexity index; COPD, chronic obstructive pulmonary disease.

23.5\% had low health literacy. Few participants (16.8\%) had current major depression or cognitive impairment $(12.6 \%)$, as measured by executive function. With respect to illness severity and control, the majority $(65.9 \%)$ had MRC dyspnea grades 4 or 5 , and $57 \%$ had uncontrolled blood pressure. Patients were prescribed an average of 11.9 (standard deviation, [SD] 4.9) medications.

Medication adherence rates were lowest for COPD medications, with $45.0 \%$ of participants having low COPD medication adherence by self-report and $52.6 \%$ by dose count (Table 2). Among participants with hypertension, $28.9 \%$ reported low adherence, and low adherence was reported by $38.8 \%$ of participants with diabetes.

\section{Medication Regimen Complexity, Total Medication Counts, and Medication}

\section{Adherence}

MRCI scores and medication counts were normally distributed and correlated strongly $(\mathrm{r}=0.77, \mathrm{p}<0.0001)$. MRCI scores did not differ significantly between those with and without adequate medication adherence to COPD, hypertension or diabetes medications, nor was there a significant association of quartile of MRCI score with any of the measures of adherence in univariate analyses (Table 2). Participants with higher total medication counts were more likely to have adequate adherence to hypertension and diabetes medications, though this association was not observed when medication count was examined as a categorical variable. No consistent observations were observed in multivariable analyses (supplementary Tables 1 and 2).

\section{Illness Control}

MRCI scores and medication counts correlated significantly with COPDSS scores $(\mathrm{r}=0.26, \mathrm{p}<0.0001$ and $\mathrm{r}=0.19, \mathrm{p}=0.0001$, respectively) and MRC dyspnea scale values $(\mathrm{r}=0.26, \mathrm{p}<0.0001$ and $\mathrm{r}=0.20, \mathrm{r}=0.0002$, respectively). Patients with higher MRCI scores and medication counts, whether as a continuous measure or in quartiles, were more likely to have high COPD severity and dyspnea scores (Table 3). Similarly, the MRCI as expressed in quartiles was significantly associated with these outcomes. MRCI and medication count were not significantly associated with blood pressure or HbAlc (among diabetics).

The highest quartile of the MRCI was significantly associated with high COPD severity score in multivariable analysis (OR 5.00, 95\% CI 1.46-17.1, p=0.01) as well as with MRC dyspnea grades 4 and 5 (OR 2.27, 95\% CI 1.03-5.03, $\mathrm{p}=0.04$ ) (Table 4). There were no significant associations of MRCI quartiles with blood pressure and hemoglobin A1c outcomes. The highest quartile of medication counts was significantly associated with MRC 
Table 3 Univariate Associations of MRCI Scores and Medication Counts with COPD Severity, and Hypertension and Diabetes Control

\begin{tabular}{|c|c|c|c|c|c|c|c|c|}
\hline & \multicolumn{2}{|c|}{ COPD Severity Score } & \multicolumn{2}{|c|}{ MRC Dyspnea Scale } & \multicolumn{2}{|c|}{ Blood Pressure } & \multicolumn{2}{|c|}{ Hemoglobin Alc } \\
\hline & $\begin{array}{l}\leq \text { I SD Above } \\
\text { Mean }\end{array}$ & $\begin{array}{l}\text { > I SD Above } \\
\text { Mean }\end{array}$ & $\begin{array}{l}\text { Levels } \\
\mathrm{I}-3\end{array}$ & $\begin{array}{l}\text { Levels } \\
4-5\end{array}$ & At Target & $\begin{array}{l}\text { Above } \\
\text { Target }\end{array}$ & $<8.0 \%$ & $\geq \mathbf{8 . 0} \%$ \\
\hline $\mathrm{N}(\%)$ & $313(78.3)$ & $87(21.8)$ & $120(34.1)$ & $232(65.9)$ & $220(57.3)$ & $164(42.7)$ & $96(74.4)$ & $33(25.6)$ \\
\hline $\mathrm{MRCl}$, mean (sd) & $31.2(13.8)$ & $38.8(14.6)^{\S}$ & $30.1(12.6)$ & $35.7(14.7)^{\ddagger}$ & $34.5(14.9)$ & $33.3(13.6)$ & $38.1(14.3)$ & $4 I .4(16.4)$ \\
\hline $\mathrm{MRCl}, \%$ & & & & & & & & \\
\hline$I^{\text {st }}$ quartile & 26.2 & $14.9^{\S}$ & 29.2 & $16.8^{\dagger}$ & 21.3 & 25.5 & 15.2 & 10.4 \\
\hline $2^{\text {nd }}$ quartile & 28.1 & 16.1 & 24.2 & 27.2 & 26.8 & 25.5 & 9.1 & 24.0 \\
\hline $3^{\text {rd }}$ quartile & 24.6 & 25.3 & 28.3 & 24.1 & 23.8 & 25.0 & 24.2 & 28.1 \\
\hline $4^{\text {th }}$ quartile & 21.1 & 43.7 & 18.3 & 31.9 & 28.1 & 24.1 & 51.5 & 27.5 \\
\hline $\begin{array}{l}\text { Medication count, } \\
\text { mean (sd) }\end{array}$ & $14.2(5.3)$ & $11.6(4.7)^{\ddagger}$ & $12.6(5.0)$ & $10.9(4.5)^{\dagger}$ & $12.0(5.1)$ & II.8 (4.5) & $13.9(5.2)$ & $14.5(4.4)$ \\
\hline Medication count, \% & & & & & & & & \\
\hline I $^{\text {st }}$ quartile (2-8) & 12.2 & $28.2 *$ & 22.4 & $34.2^{*}$ & 26.8 & 26.2 & 14.6 & 9.1 \\
\hline $2^{\text {nd }}$ quartile $(9-1 \mathrm{I})$ & 18.4 & 25.9 & 24.6 & 24.2 & 23.6 & 26.8 & 21.9 & 15.2 \\
\hline $3^{\text {rd }}$ quartile $(12-15)$ & 34.7 & 25.1 & 26.7 & 25.8 & 25.9 & 26.8 & 24.0 & 39.4 \\
\hline $4^{\text {th }}$ quartile $(16-29)$ & 34.7 & 20.8 & 26.3 & 15.8 & 23.6 & 20.1 & 39.6 & 36.4 \\
\hline
\end{tabular}

Note: $* \mathrm{P}<0.05,{ }^{\dagger} \mathrm{P}<0.01,{ }^{\ddagger} \mathrm{P}<0.001,{ }^{\S} \mathrm{P}<0.0001$.

Abbreviations: $\mathrm{MRCl}$, medication regimen complexity index; COPD, chronic obstructive pulmonary disease; MRC, Medical Research Council.

dyspnea grades 4 and 5 (OR 2.90, 95\% CI 1.31-6.37, $\mathrm{p}=0.009$ ), but no other significant associations of quartile of medication count with COPD severity, dyspnea or blood pressure were observed (Table 5).

\section{Discussion}

In this study, while we found that medication regimen complexity was associated with greater COPD symptoms, there was no statistically significant associations between regimen complexity and medication adherence. These findings suggest that simplifying medication regimens for the sake of improved medication adherence among COPD patients alone may not be an effective strategy.

While a wealth of studies have identified contributors or correlates of medication adherence among COPD patients, this is the first to examine the association with medication regimen complexity. Prior studies have examined regimen complexity with medication adherence in other disease contexts and reported mixed results. Bazargan et al found greater non-adherence, for medication use in general, among those with MRCI scores $\geq 10 .{ }^{14}$ Parker and colleagues, in contrast, found no association of medication adherence with MRCI among patients with chronic kidney disease. ${ }^{11}$ A systematic review identified 7 studies of low to moderate quality that linked the MRCI with medication adherence across a range of medical conditions. ${ }^{13}$ Variability in associations between MRCI and adherence may be the result of heterogeneity of factors that independently affect adherence, including modality of medication delivery (eg, oral vs inhaled), chronic illness of study and extent of multimorbidity in the study population, and study population demographics. Our study was conducted among inner city, mostly low-income adults with COPD and multiple comorbidities, and comparisons of our findings to others should consider the context of our study when interpreting it results and application to other populations.

There a host of reasons to reduce polypharmacy in older adults, such as improving quality of life $\mathrm{e}^{29}$ and reducing the risk of adverse events. ${ }^{30}$ Some reports have found that simplifying medication regimens does improve adherence (mostly in HIV infected adults), ${ }^{31}$ but no regimen simplification interventions have been tested in people with COPD. Reducing complexity ought to be a goal of all clinicians when clinically indicated. In the case of COPD, however, our results suggest that it may not result in improved adherence to inhaled medications.

Much of the published research on medication regimen complexity focuses on associations with illness 
Table 4 Multivariate Associations of MRCI Count with COPD Severity, and Hypertension and Diabetes Control

\begin{tabular}{|c|c|c|c|c|c|c|c|c|}
\hline & \multicolumn{2}{|c|}{$\begin{array}{c}\text { High COPD Severity } \\
\text { Score* }\end{array}$} & \multicolumn{2}{|c|}{$\begin{array}{l}\text { High MRC Dyspnea } \\
\text { Scale Score }\end{array}$} & \multicolumn{2}{|c|}{$\begin{array}{c}\text { Blood Pressure Not } \\
\text { at Target }\end{array}$} & \multicolumn{2}{|c|}{$\begin{array}{c}\text { Hemoglobin Alc } \\
\geq 8.0 \%\end{array}$} \\
\hline & OR $(95 \% \mathrm{Cl})$ & $\mathbf{P}$ & OR $(95 \% \mathrm{Cl})$ & $\mathbf{P}$ & OR $(95 \% \mathrm{Cl})$ & $\mathbf{P}$ & OR $(95 \% \mathrm{Cl})$ & $\mathbf{P}$ \\
\hline \multicolumn{9}{|l|}{ MCRI } \\
\hline$I^{\text {st }}$ quartile & Ref. & & Ref. & & Ref. & & Ref. & \\
\hline $2^{\text {nd }}$ quartile & $1.33(0.33-5.4 \mathrm{I})$ & 0.69 & $1.86(0.89-3.89)$ & 0.10 & $0.78(0.4 I-1.50)$ & 0.46 & $0.35(0.05-2.7 I)$ & 0.31 \\
\hline $3^{\text {rd }}$ quartile & $2.58(0.70-9.43)$ & 0.15 & $1.35(0.64-2.85)$ & 0.44 & $1.02(0.52-2.00)$ & 0.95 & $1.25(0.18-8.82)$ & 0.82 \\
\hline $4^{\text {th }}$ quartile & $5.00(1.46-17.1)$ & 0.01 & $2.27(1.03-5.03)$ & 0.04 & $0.67(0.34-1.35)$ & 0.26 & $1.50(0.22-10.2)$ & 0.68 \\
\hline \multicolumn{9}{|l|}{ Age Category } \\
\hline $50-59$ & Ref. & & Ref. & & Ref. & & Ref. & \\
\hline $60-69$ & $1.67(0.57-4.92)$ & 0.35 & $0.78(0.35-1.83)$ & 0.57 & $2.49(1.23-5.03)$ & 0.01 & $1.17(0.29-4.76)$ & 0.82 \\
\hline $70-79$ & $1.43(0.44-4.70)$ & 0.55 & $0.85(0.35-2.05)$ & 0.72 & $\mathrm{I} .40(0.68-2.89)$ & 0.36 & $0.09(0.01-0.75)$ & 0.03 \\
\hline $80+$ & $1.42(0.33-8.94)$ & 0.52 & $2.19(0.74-6.46)$ & 0.16 & $0.67(0.26-1.72)$ & 0.41 & $1.69(0.19-15.1)$ & 0.64 \\
\hline Male Sex & $1.48(0.66-3.33)$ & 0.34 & $1.24(0.71-2.16)$ & 0.46 & $0.81(0.50-1.33)$ & 0.41 & $0.64(0.18-2.33)$ & 0.51 \\
\hline \multicolumn{9}{|l|}{ Race and ethnicity } \\
\hline White, non-Hispanic & Ref. & & Ref. & & Ref. & & Ref. & \\
\hline Black, non-Hispanic & $1.63(0.55-4.87)$ & 0.38 & $2.7 \mid(1.27-5.82)$ & 0.01 & $0.75(0.39-1.45)$ & 0.39 & $1.19(0.20-7.18)$ & 0.85 \\
\hline Hispanic & $1.42(0.36-5.66)$ & 0.62 & $3.02(0.98-9.33)$ & 0.05 & $1.49(0.59-3.73)$ & 0.40 & $1.54(0.23-10.5)$ & 0.66 \\
\hline \multicolumn{9}{|l|}{ Education } \\
\hline College graduate & Ref. & & Ref. & & Ref. & & Ref. & \\
\hline Some college & $1.35(0.45-4.06)$ & 0.60 & $1.05(0.54-2.05)$ & 0.88 & $0.92(0.49-1.73)$ & 0.80 & I.8I (0.30-II.I) & 0.52 \\
\hline High school graduate & $2.66(0.85-8.30)$ & 0.09 & $1.22(0.56-2.66)$ & 0.62 & $0.49(0.29-1.17)$ & 0.13 & I.II (0.14-8.63) & 0.92 \\
\hline $\begin{array}{l}\text { Did not graduate high } \\
\text { school }\end{array}$ & $0.17(0.02-1.70)$ & 0.13 & $1.44(0.44-4.76)$ & 0.55 & $0.80(0.32-2.05)$ & 0.65 & $4.62(0.46-46.0)$ & 0.19 \\
\hline English proficiency, low & $0.78(0.07-8.76)$ & 0.84 & - & & $0.30(0.07-1.28)$ & 0.10 & $1.62(0.13-20.8)$ & 0.71 \\
\hline Low health literacy & $0.88(0.32-2.4 I)$ & 0.81 & $1.46(0.64-3.33)$ & 0.36 & $0.97(0.50-1.89)$ & 0.92 & $1.23(0.29-5.25)$ & 0.78 \\
\hline \multicolumn{9}{|l|}{ Insurance } \\
\hline Private & Ref. & & Ref. & & Ref. & & Ref. & \\
\hline Any Medicaid & $3.44(1.19-9.94)$ & 0.02 & $1.87(0.83-4.22)$ & 0.13 & $1.08(0.54-2.15)$ & 0.83 & $1.05(0.20-5.48)$ & 0.95 \\
\hline Medicare & $0.80(0.18-3.52)$ & 0.77 & $1.73(0.72-4.17)$ & 0.22 & $1.63(0.75-3.55)$ & 0.22 & $1.90(0.23-15.7)$ & 0.55 \\
\hline Depression & $2.61(1.05-6.47)$ & 0.04 & $2.36(1.04-5.31)$ & 0.04 & $0.59(0.30-1.17)$ & 0.13 & $0.50(0.10-2.39)$ & 0.38 \\
\hline $\begin{array}{l}\text { Executive function } \\
\text { impairment }\end{array}$ & $0.67(0.17-2.68)$ & 0.57 & $0.96(0.35-2.66)$ & 0.94 & $0.77(0.35-1.69)$ & 0.51 & $2.99(0.46-19.4)$ & 0.25 \\
\hline
\end{tabular}

Notes: *COPD severity score $>$ I standard deviation above the mean value for the study sample. ${ }^{\dagger}$ MRC Dyspnea Scale score $>3$.

Abbreviations: COPD, chronic obstructive pulmonary disease; MRC, Medical Research Council; $\mathrm{MRCl}$, medication regimen complexity index.

severity and is consistent with our findings. George et al developed the MRCI using data from a cohort of 134 COPD patients with FEV1 $<60 \%$ and reported greater illness severity among patients with higher MRCI scores. ${ }^{15}$ Negewo and colleagues reported that the MRCI was associated with COPD severity among 222 Australian patients with forced expiratory volume at 1 second $\left(\mathrm{FEV}_{1}\right)<70 \%{ }^{12}$ They also found that MRCI was significantly and inversely associated with post- bronchodilator $\mathrm{FEV}_{1}$ and the 6-minute walk test distance. These examples provide evidence for an expected association, that patients with more advanced illness take more medications, and by extension, have greater regimen complexity. While medications do have side effects, and some may be substantial enough to affection function and quality of life, it is more likely that overall illness severity dictated prescribing of medications for patients in this study than the other way around. 
Table 5 Multivariate Associations of Medication Count with COPD Severity and Hypertension Control

\begin{tabular}{|c|c|c|c|c|c|c|}
\hline & \multicolumn{2}{|c|}{ High COPD Severity Score* } & \multicolumn{2}{|c|}{ High MRC Dyspnea Scale Score ${ }^{\dagger}$} & \multicolumn{2}{|c|}{$\begin{array}{c}\text { Blood Pressure Not } \\
\text { at Target }\end{array}$} \\
\hline & OR $(95 \% \mathrm{Cl})$ & $\mathbf{P}$ & OR $(95 \% \mathrm{Cl})$ & $\mathbf{P}$ & OR (95\% Cl) & $\mathbf{P}$ \\
\hline \multicolumn{7}{|l|}{ Medication count } \\
\hline$I^{\text {st }}$ quartile & Ref. & & Ref. & & Ref. & \\
\hline $2^{\text {nd }}$ quartile & $1.80(0.53-6.14)$ & 0.35 & $1.40(0.67-2.93)$ & 0.73 & $0.92(0.48-1.77)$ & 0.81 \\
\hline $3^{\text {rd }}$ quartile & $2.38(0.74-7.73)$ & 0.15 & $1.65(0.80-3.40)$ & 0.17 & $0.97(0.51-1.83)$ & 0.92 \\
\hline $4^{\text {th }}$ quartile & $3.22(0.94-11.0)$ & 0.06 & $2.90(1.31-6.37)$ & 0.009 & $1.43(0.7 \mid-2.89)$ & 0.32 \\
\hline
\end{tabular}

Notes: Analyses adjusted for age, sex, race and ethnicity, education, English language proficiency, level of health literacy, insurance, depression and cognitive impairment. Model for hemoglobin Alc did not converge. ${ }^{*}$ COPD severity score $>I$ standard deviation above the mean value for the study sample. ${ }^{\dagger}$ MRC Dyspnea Scale score $>3$ Abbreviations: COPD, chronic obstructive pulmonary disease; MRC, Medical Research Council; $\mathrm{MRCl}$, medication regimen complexity index.

Our study, like that of Negewo et al, also found a strong correlation between number of medications and MRCI, and a similar association of medications and MRCI with measures of COPD severity. This finding, in combination with the lack of a significant association between MRCI and medication adherence, suggests the limited value of the MRCI for clinical and research applications in the COPD context. Given the considerable work required to calculate the MRCI, involving collection of data on mode of administration, dose, dosing frequency, and other parameters for each medication, a simple count of prescribed medications may be a sufficient representation of regimen complexity for many analytic purposes.

Strengths of this study include the large sample of study subjects, racial and ethnic diversity, and use of both objective and subjective measures of COPD medication adherence. Notable limitations include the absence of objective adherence measures for hypertension and diabetes. There was also a small subset of patients with comorbid diabetes and therefore less statistical power for analyses of diabetes medication adherence and diabetes control.

Medication regimen complexity, as measured by the MRCI, is not associated with COPD medication adherence, and while our data suggest that it is a reliable indicator of illness severity, and could serve as a useful proxy measure for disease severity, it is burdensome to collect the data for its measure and may not be more useful than a simple count of medications.

\section{Ethics Statement}

This study was conducted in accordance with the Declaration of Helsinki.

\section{Author Contributions}

All authors made a significant contribution to the work reported, whether that is in the conception, study design, execution, acquisition of data, analysis and interpretation, or in all these areas; took part in drafting, revising or critically reviewing the article; gave final approval of the version to be published; have agreed on the journal to which the article has been submitted; and agree to be accountable for all aspects of the work.

\section{Funding}

National Heart Lung and Blood Institute, R01 HL126508

\section{Disclosure}

Dr. Wolf reports grants from Amgen, Eli Lilly, AbbVie, and Lundbeck, personal fees from Sanofi and Luton UK, and grants and personal fees from Pfizer and Merck, Sharpe \& Dohme. Dr. Wisnivesky reports grants and personal fees from Sanofi, personal fees from Banook and Atea, and grants from Arnold. The authors report no other conflicts of interest in this work.

\section{References}

1. Cecere LM, Slatore CG, Uman JE, et al. Adherence to long-acting inhaled therapies among patients with chronic obstructive pulmonary disease (COPD). COPD. 2012;9(3):251-258. doi:10.3109/ 15412555.2011.650241

2. O'Conor R, Muellers K, Arvanitis M, et al. Effects of health literacy and cognitive abilities on COPD self-management behaviors: a prospective cohort study. Respir Med. 2019;160:105630.

3. George J, Kong DC, Thoman R, Stewart K. Factors associated with medication nonadherence in patients with COPD. Chest. 2005;128 (5):3198-3204.

4. Khdour MR, Hawwa AF, Kidney JC, Smyth BM, McElnay JC. Potential risk factors for medication non-adherence in patients with chronic obstructive pulmonary disease (COPD). Eur $J$ Clin Pharmacol. 2012;68(10):1365-1373. 
5. Perez-Benzo GM, Muellers K, Chen S, et al. Identifying behavioral phenotypes in chronic illness: self-management of COPD and comorbid hypertension. Patient Educ Couns. 2020;S0738-3991(20):30456.

6. Zivin K, Ratliff S, Heisler MM, Langa KM, Piette JD. Factors influencing cost-related nonadherence to medication in older adults: a conceptually based approach. Value Health. 2010;13(4):338-345.

7. Sofianou A, Martynenko M, Wolf MS, et al. Asthma beliefs are associated with medication adherence in older asthmatics. $J$ Gen Intern Med. 2013;28(1):67-73.

8. Soones TN, Lin JL, Wolf MS, et al. Pathways linking health literacy, health beliefs, and cognition to medication adherence in older adults with asthma. J Allergy Clin Immunol. 2017;139(3):804-809.

9. Divo M, Celli BR. Multimorbidity in patients with chronic obstructive pulmonary disease. Clin Chest Med. 2020;41(3):405-419.

10. Noteboom B, Jenkins S, Maiorana A, Cecins N, Ng C, Hill K. Comorbidities and medication burden in patients with chronic obstructive pulmonary disease attending pulmonary rehabilitation. Journal of Cardiopulmonary Rehabilitation and Prevention. 2014;34(1):75-79. doi:10.1097/HCR.0000000000000036

11. Parker K, Bull-Engelstad I, Aasebø W, et al. Medication regimen complexity and medication adherence in elderly patients with chronic kidney disease. Int Symposium Home Hemodialysis. 2019;23 (3):333-342.

12. Negewo NA, Gibson PG, Wark PA, Simpson JL, McDonald VM. Treatment burden, clinical outcomes, and comorbidities in COPD: an examination of the utility of medication regimen complexity index in COPD. Int J Chron Obstruct Pulmon Dis. 2017;12:2929-2942.

13. Alves-Conceição V, Rocha KSS, Silva FVN, Silva ROS, Silva DTD, Lyra DP Jr. Medication regimen complexity measured by MRCI: a systematic review to identify health outcomes. Ann Pharmacother. 2018;52(11):1117-1134

14. Bazargan M, Smith J, Yazdanshenas H, Movassaghi M, Martins D, Orum G. Non-adherence to medication regimens among older African-American adults. BMC Geriatr. 2017;17(1):163.

15. George J, Phun YT, Bailey MJ, Kong DC, Stewart K. Development and validation of the medication regimen complexity index. Ann Pharmacother. 2004;38(9):1369-1376.

16. Lehmann A, Aslani P, Ahmed R, et al. Assessing medication adherence: options to consider. Int J Clin Pharm. 2014;36(1):55-69.

17. Thompson K, Kulkarni J, Sergejew AA. Reliability and validity of a new Medication Adherence Rating Scale (MARS) for the psychoses. Schizophr Res. 2000;42(3):241-247.

18. Cohen JL, Mann DM, Wisnivesky JP, et al. Assessing the validity of self-reported medication adherence among inner-city asthmatic adults: the Medication Adherence Report Scale for Asthma. Ann Allergy Asthma Immunol. 2009;103(4):325-331.
19. Eisner MD, Trupin L, Katz PP, et al. Development and validation of a survey-based COPD severity score. Chest. 2005;127(6):1890-1897.

20. Bestall JC, Paul EA, Garrod R, Garnham R, Jones PW, Wedzicha JA. Usefulness of the Medical Research Council (MRC) dyspnoea scale as a measure of disability in patients with chronic obstructive pulmonary disease. Thorax. 1999;54(7):581-586.

21. James PA, Oparil S, Carter BL, et al. 2014 evidence-based guideline for the management of high blood pressure in adults: report from the panel members appointed to the Eighth Joint National Committee (JNC 8). JAMA. 2014;311(5):507-520.

22. Cifu AS, Davis AM. Prevention, detection, evaluation, and management of high blood pressure in adults. JAMA. 2017;318 (21):2132-2134

23. American Diabetes Association. Standards of Medical Care in Diabetes--2020. Diabetes Care. 2020;43(Supplement 1):S66-S76.

24. Badr H, Federman AD, Wolf M, Revenson TA, Wisnivesky JP. Depression in individuals with chronic obstructive pulmonary disease and their informal caregivers. Aging Ment Health. 2017;21 (9):975-982.

25. Korpershoek Y, Bos-Touwen ID, de Man-van Ginkel JM, Lammers JW, Schuurmans MJ, Trappenburg J. Determinants of activation for self-management in patients with COPD. Int $J$ Chron Obstruct Pulmon Dis. 2016;11:1757-1766.

26. Freedland KE, Skala JA, Carney RM, et al. The Depression Interview and Structured Hamilton (DISH): rationale, development, characteristics, and clinical validity. Psychosom Med. 2002;64(6):897-905.

27. Chew LD, Griffin JM, Partin MR, et al. Validation of screening questions for limited health literacy in a large VA outpatient population. J Gen Intern Med. 2008;23(5):561-566.

28. Salthouse TA. What cognitive abilities are involved in trail-making performance? Intelligence. 2011;39(4):222-232.

29. Lalic S, Jamsen KM, Wimmer BC, et al. Polypharmacy and medication regimen complexity as factors associated with staff informant rated quality of life in residents of aged care facilities: a cross-sectional study. Eur J Clin Pharmacol. 2016;72(9):1117-1124.

30. Wimmer BC, Bell JS, Fastbom J, Wiese MD, Johnell K. Medication regimen complexity and number of medications as factors associated with unplanned hospitalizations in older people: a population-based cohort study. J Gerontol A Biol Sci Med Sci. 2016;71(6):831-837.

31. Elnaem MH, Irwan NA, Abubakar U, Syed Sulaiman SA, Elrggal ME, Cheema E. Impact of medication regimen simplification on medication adherence and clinical outcomes in patients with long-term medical conditions. Patient Prefer Adherence. 2020;14:2135-2145.

\section{Publish your work in this journal}

The International Journal of COPD is an international, peer-reviewed journal of therapeutics and pharmacology focusing on concise rapid reporting of clinical studies and reviews in COPD. Special focus is given to the pathophysiological processes underlying the disease, intervention programs, patient focused education, and self management protocols. This journal is indexed on PubMed Central, MedLine and CAS. The manuscript management system is completely online and includes a very quick and fair peer-review system, which is all easy to use. Visit http://www.dovepress.com/testimonials.php to read real quotes from published authors. 